\title{
Fitting the Variance-Gamma Model: A Goodness-of-Fit Check for Emerging Markets
}

\author{
Ahmet Göncï* \\ Xi'an Jiaotong \\ Liverpool University
}

\author{
Mehmet Oğuz Karahan** \\ Boğaziçi University
}

\author{
Tolga Umut Kuzubaş**** \\ Boğaziçi University
}

\begin{abstract}
Variance-Gamma model is widely used for option pricing; however there has been little research on the empirical performance of this model for emerging market economies. In this paper we evaluate the goodness-of-fit of the Variance-Gamma model using index returns data from ten different emerging markets. Based on the Chi-square, AndersonDarling and Kolmogorov-Smirnov goodness-of-fit test statistics, we show that the Variance-Gamma model fits the dataset well and improves upon the fit of the normal distribution for emerging stock market indices. Furthermore, under the Variance-Gamma model, closed form solutions for pricing European call and put options exist and model parameters can be efficiently estimated via the maximum likelihood method.
\end{abstract}

Keywords: Variance-Gamma model, goodness-of-fit, emerging markets.

\section{Varyans-Gama Modeli: Gelişen Piyasalar için Bir Uyum İyiliği Analizi}

\section{Özet}

Varyans-Gama modeli opsiyon fiyatlanmasında sıkça kullanıldığı halde bu modelin gelişen piyasalardaki ampirik performansı üzerindeki araştırmalar sınırlıdır. Bu makalede on farklı gelişen piyasa ekonomisinin hisse senedi endeks getiri verileri kullanılarak Varyans-Gama modelinin uyum iyiliği değerlendirilmektedir. Ki-kare, Anderson-Darling ve Kolmogorov-Smirnov uyum iyiliği test istatistikleri kullanılarak, Varyans-Gama modelinin gelişen piyasalar hisse senedi endeks getirilerine oldukça uyumlu olduğu ve normal dağılıma göreli olarak uyumu arttırdığı gösterilmiştir. Aynı zamanda, VaryansGama modeli altında, Avrupa tipi alım ve satım opsiyonlarının fiyatları için kapalı yapıda çözümler mevcuttur ve model parametreleri en büyük olabilirlik yöntemi ile etkin bir şekilde kestirilebilmektedir.

Anahtar kelimeler: Varyans-Gama modeli, uyum iyiliği, gelişen piyasalar.

\footnotetext{
* Ahmet Göncü is an Assistant Professor in the Department of Mathematical Sciences at Xi'an Jiaotong Liverpool University, Suzhou, Jiangsu 215123, China. E-mail: goncuahm@gmail.com

** Mehmet Oğuz Karahan is a Research Associate in the Center for Economics and Econometrics at Boğaziçi University, 34342 , Bebek, Istanbul, Turkey. E-mail: oguzkarahan@gmail.com

*** Tolga Umut Kuzubaş is an Assistant Professor in the Department of Economics at Boğaziçi University, 34342, Bebek, Istanbul, Turkey. E-mail: umutkuzubas@gmail.com
} 
$\mathrm{S}$ tock returns are often characterized by leptokurtosis and they exhibit volatility clustering. ${ }^{[1]}$ Yet the Black-Scholes model has been the dominant method for pricing financial derivatives, even though its fundamental assumptions such as normality of stock returns is not consistent with empirical observations.

Financial derivative pricing builds upon a suitable stochastic process which characterizes an empirical distribution of stock returns. Madan and Senata (1990) argue that such a process should possess the following properties: (1) long tailedness relative to the normal distribution; (2) finite moments (for at least the lower powers of returns); (3) a continuous-time stochastic process with independent stationary increments such that the distribution of any increment belongs to the same distribution family; and (4) an extension to multivariate processes with elliptic multivariate distributions. The Black-Scholes model and the use of geometric Brownian motion satisfy all but the first of the above properties.

The Variance-Gamma (VG) model is a pure jump process with a large number of small jumps. In this sense, it resembles the continuous paths of Brownian motion. On the other hand, probability distribution function implied by the VG model can capture a higher frequency of extreme events than normal distribution. Additionally, the availability of closed-form solutions for European call and put options increases the attractiveness of the VG model in practice. For example, the Bloomberg software incorporates the VG model and provides built-in pricing functions (Carr et al., 2007).

Apart from the Normal Inverse Gaussian (NIG) process (Barndorff-Nielsen, 1997, Barndorff-Nielsen, 1998), the VG process is the only generalized hyperbolic process which is closed under convolution, so that the stock price at any point in time is VG distributed (Bibby and Sorensen, 2003). Therefore, it is a natural alternative to the Black-Scholes model.

While the use of the VG model has gained popularity for option pricing, there has been limited research in terms of its fit to historical returns. Madan and Seneta (1987) compare the VG model with the symmetric stable distribution and compound events models (Press, 1967) using the Chi-square goodness-of-fit statistic for log-returns of 19 large stocks listed on the Sydney Stock Exchange. They find that the VG model achieves the minimum Chi-square statistic for 12 out of 19 stocks. Hurst and Platen (1997), Madan et al. (1998) and Seneta (2004) evaluate the performance of the VG model utilizing Chi-square and Kolmogorov-Smirnov goodness-of-fit tests.

The VG model has been empirically shown to improve the out-of-sample pricing performance compared to the Black-Scholes or Merton's jump-diffusion models (Daal and Madan, 2005). For developed stock markets, Hurst and Platen (1997) test the symmetric case of the VG model which reduces to a parametric special case of the symmetric generalized hyperbolic distribution. Rathegeber et al. (2013) suggest that the fit of the VG model can further be improved by introducing a regime-switching model for selection of the estimation sample. They provide evidence that, for Dow Jones stocks, the VG model yields favorable goodness-of-fit statistics. Finlay (2009) extends

[1] See Cont (2001) for an extensive analysis. 
the VG model to account for the stochastic volatility in returns and the long-memory effects in squared returns.

Emerging markets are often characterized by higher unconditional and conditional moments in their empirical return distributions relative to developed markets (see Bekeart and Harvey, 1995; Harvey, 1995; Bekeart and Harvey, 1997, and Engle and Rangel, 2008). Even within emerging markets there are variations in the tail behavior of empirical returns (Gencay and Selçuk, 2004). Therefore, a good fit of a particular distribution in the developed markets does not necessitate a similar performance in the emerging markets.

Santis and İmrohoroğlu (1997) and Li and Rose (2009) also document that emerging markets have higher tail probabilities. A low level of liquidity in emerging markets compared to the developed markets also leads to significant deviations (see Bekaert et al., 2009).

In this study, we compare the empirical log-return distributions of 10 emerging market indices to the theoretical distributions implied by the VG model. This study contributes to the existing literature by verifying the goodness-of-fit of the VG model in the emerging markets. To the best of our knowledge, this is the first paper investigating the fit of the VG model for emerging markets.

We find that the fit of the VG model is quite satisfactory in terms of Chi-square, Anderson-Darling and Kolmogorov-Smirnov goodness-of-fit statistics. Furthermore, contrary to the empirical results of Hurst and Platen (1997), which are provided for five developed markets, the VG model yields much smaller Anderson-Darling test statistics in all of the emerging markets considered in this study.

The rest of the paper is organized as follows: In the next section, we provide the Variance-Gamma model and its properties. Section 3 describes the dataset used in the study. In Section 4, we discuss estimation procedures and goodness-of-fit statistics. Section 5 concludes the paper.

\section{Modeling Stock Prices under the Variance-Gamma Model}

The VG model assumes that the stock price process follows (Seneta, 2004)

$$
S_{t}=S_{t-1} \exp \left(c \Delta t+\theta \tau_{t}+\sigma\left(W\left(T_{t}\right)-W\left(T_{t-1}\right)\right)\right),
$$

where $\left\{T_{t}\right\}$ is a Gamma process with stationary differences given as $\tau_{t}=T_{t}-T_{t-1}, W(\cdot)$ is standard Brownian motion and $c, \theta, \sigma>0$ are real constants. Therefore, the log-return process is given by

$$
\ln \left(\frac{S_{t}}{S_{t-1}}\right)=X(t)=c+\theta\left(T_{t}-T_{t-1}\right)+\sigma\left(W\left(T_{t}\right)-W\left(T_{t-1}\right)\right) .
$$

We assume $E\left[\tau_{t}\right]=1$ to make the expected activity time change over unit calendar time equal to one unit, the scaling change in time being absorbed into $\theta$ and $\sigma$, noting that

$$
\sigma\left(W\left(T_{t}\right)-W\left(T_{t-1}\right)\right)^{d}=\sigma\left(T_{t}-T_{t-1}\right)^{1 / 2} W(1) .
$$


Under the VG model, log-return of stock prices, denoted by $X(t)=\ln \left(S_{t} / S_{t-1}\right)$ has the following probability density function

$$
f_{X}(x)=\frac{2 \exp \left(\theta(x-c) / \sigma^{2}\right)}{\sigma \sqrt{2 \pi} v^{1 / v} \Gamma(1 / v)}\left(\frac{|x-c|}{\sqrt{2 \sigma^{2} / v+\theta^{2}}}\right)^{\frac{1}{v}-\frac{1}{2}} K_{\frac{1}{v}-\frac{1}{2}}\left(\frac{|x-c| \sqrt{2 \sigma^{2} / v+\theta^{2}}}{\sigma^{2}}\right)
$$

for $-\infty<x<\infty$ (see Seneta, 2004), where $c$ is the location, $\theta$ is skewness, $\sigma$ is the scale and $v>0$ is the shape parameter. $K_{\eta}($.$) is the modified Bessel function of the$ second kind. The p.d.f.s of VG models are generated by MATLAB software, which has the built-in modified Bessel function of the second kind.

In Seneta (2004), the method of moments estimators are given as:

$$
\begin{aligned}
& \mu:=E\left[X_{t}\right]=c+\theta \\
& \operatorname{var}\left(X_{t}\right)=\sigma^{2}+\theta^{2} v \\
& \beta=\frac{2 \theta^{3} v^{2}+3 \sigma^{2} \theta v}{\left(\theta^{2} v+\sigma^{2}\right)^{3 / 2}} \text { (skewness) } \\
& \kappa=3+\frac{3 \sigma^{4} v+12 \sigma^{2} \theta^{2} v^{2}+6 \theta^{4} v^{3}}{\left(\theta^{2} v+\sigma^{2}\right)^{2}} \text { (kurtosis) }
\end{aligned}
$$

For small values of $\theta$, one can ignore higher order terms of $\theta$, and thus the method of moments estimators simplify to:

$$
\begin{aligned}
& \mu=E\left[X_{t}\right]=c+\theta \\
& \operatorname{var}\left(X_{t}\right)=\sigma^{2} \\
& \beta=\frac{3 \theta v}{\sigma} \quad \text { (skewness) } \\
& \kappa=3(1+v) \quad \text { (kurtosis). }
\end{aligned}
$$

The detailed analysis of the VG model is given in Madan and Seneta (1987), Madan et al. (1998) and Seneta (2004). An important advantage of the VG model is the availability of an analytical option pricing formula for European type call/put options (Madan et al., 1998). This convenience facilitates pricing of European options once parameters of the VG model are estimated.

\section{Data}

We utilize a dataset which consists of daily composite index returns for ten emerging markets: Turkey, China, India, Brazil, Russia, Indonesia, Malaysia, Thailand, South Africa and Mexico. Our dataset covers the period from January 1, 1998 to May 6, 2013. Descriptive statistics of daily log-returns are summarized in Table 1. Table 1 shows that emerging market index returns have high kurtosis values, which confirms that emerging market returns have heavier tails than implied by the normal distribution. 
Table 1

Descriptive Statistics of Daily Log-returns of Stock Market Indices

\begin{tabular}{l|l|l|l|l|l|l}
\hline & Mean & Stdev & Skewness & Kurtosis & Min & Max \\
\hline Turkey & 0.0009 & 0.0259 & 0.0957 & 8.9467 & -0.1998 & 0.1777 \\
\hline China & 0.0002 & 0.0162 & -0.0804 & 7.1727 & -0.0926 & 0.0940 \\
\hline India & 0.0004 & 0.0167 & -0.1298 & 8.5579 & -0.1181 & 0.1599 \\
\hline Brazil & 0.0004 & 0.0213 & 0.5319 & 16.8791 & -0.1723 & 0.2882 \\
\hline Russia & 0.0007 & 0.0284 & 0.2292 & 16.0124 & -0.2066 & 0.2750 \\
\hline Indonesia & 0.0007 & 0.0168 & -0.1832 & 10.2295 & -0.1273 & 0.1313 \\
\hline Malaysia & 0.0003 & 0.0136 & 0.5686 & 69.5893 & -0.2415 & 0.2082 \\
\hline Thailand & 0.0004 & 0.0165 & -0.0069 & 10.7973 & -0.1606 & 0.1135 \\
\hline South Africa & 0.0005 & 0.0131 & -0.2678 & 6.4942 & -0.0795 & 0.0683 \\
\hline Mexico & 0.0005 & 0.0152 & 0.1452 & 8.1717 & -0.1034 & 0.1215 \\
\hline
\end{tabular}

\section{Estimation}

In this section, we provide model parameters estimated by the method of moments and maximum likelihood estimators. The method of moments estimator under the VG model is given in Equations (5)-(9). Estimated parameters for the symmetric case of the VG model $(\theta=0)$ are provided in Table 2 and for the asymmetric case in Table 3 . We observe that the estimated $\theta$ values are small, suggesting that the method of moments estimators can be simplified by ignoring the higher order terms of $\theta$.

The method of moments estimates are used as the initial values of parameters in the maximum likelihood estimation. The results of maximum likelihood estimation applied to the mean subtracted daily log-returns are presented in Table 4.

Table 2

Fitted Parameters of the VG Model (symmetric case, $\theta=0$ ) by Method of Moments Estimation.

\begin{tabular}{l|l|l|l}
\hline & $\boldsymbol{\mu}$ & $\sigma$ & $\boldsymbol{v}$ \\
\hline Turkey & 0.0009 & 0.0259 & 1.9822 \\
\hline China & 0.0002 & 0.0162 & 1.3909 \\
\hline India & 0.0004 & 0.0167 & 1.8526 \\
\hline Brazil & 0.0004 & 0.0213 & 4.6264 \\
\hline Russia & 0.0007 & 0.0284 & 4.3375 \\
\hline Indonesia & 0.0007 & 0.0168 & 2.4098 \\
\hline Malaysia & 0.0003 & 0.0136 & 2.2196 \\
\hline Thailand & 0.0004 & 0.0165 & 2.5991 \\
\hline South Africa & 0.0005 & 0.0131 & 1.1647 \\
\hline Mexico & 0.0005 & 0.0152 & 1.7239 \\
\hline
\end{tabular}


Table 3

Fitted Parameters of the VG Model (asymmetric case) by Method of Moments Estimation.

\begin{tabular}{l|l|l|l|l}
\hline & $\mu$ & $\theta$ & $\sigma$ & $\boldsymbol{\nu}$ \\
\hline Turkey & 0.0009 & 0.0004 & 0.0259 & 1.9822 \\
\hline China & 0.0002 & -0.0003 & 0.0162 & 1.3909 \\
\hline India & 0.0004 & -0.0004 & 0.0167 & 1.8526 \\
\hline Brazil & 0.0004 & 0.0008 & 0.0213 & 4.6264 \\
\hline Russia & 0.0007 & 0.0005 & 0.0284 & 4.3375 \\
\hline Indonesia & 0.0007 & -0.0004 & 0.0168 & 2.4098 \\
\hline Malaysia & 0.0003 & 0.0001 & 0.0136 & 2.2196 \\
\hline Thailand & 0.0004 & 0.0 & 0.0165 & 2.5991 \\
\hline South Africa & 0.0005 & -0.0010 & 0.0131 & 1.1647 \\
\hline Mexico & 0.0005 & 0.0004 & 0.0152 & 1.7239 \\
\hline
\end{tabular}

Table 4

Fitted Parameters of the VG Model (asymmetric case) by Maximum Likelihood Estimation (MLE applied to the mean excess daily log-returns)

\begin{tabular}{l|l|l|l|l}
\hline & $\mu=\bar{x}$ & $\theta$ & $\sigma$ & $\nu$ \\
\hline Turkey & 0.0009 & -0.0007 & 0.0250 & 0.9306 \\
\hline China & 0.0002 & -0.0007 & 0.0159 & 0.9429 \\
\hline India & 0.0004 & -0.0016 & 0.0163 & 0.7857 \\
\hline Brazil & 0.0004 & -0.0013 & 0.0204 & 0.7030 \\
\hline Russia & 0.0007 & -0.0016 & 0.0263 & 1.1771 \\
\hline Indonesia & 0.0007 & -0.0011 & 0.0160 & 0.9651 \\
\hline Malaysia & 0.0003 & -0.0002 & 0.0113 & 1.3872 \\
\hline Thailand & 0.0004 & -0.0001 & 0.0159 & 0.8700 \\
\hline South Africa & 0.0005 & -0.0013 & 0.0128 & 0.6134 \\
\hline Mexico & 0.0005 & -0.0009 & 0.0148 & 0.8899 \\
\hline
\end{tabular}

\section{Goodness-of-fit tests}

Madan and Seneta (1987) provide evidence that the symmetric case of the VG model performs well for 12 out of 19 stocks on the Sydney Stock Exchange, using a Chi-square goodness-of-fit test. Seneta (2004) suggests that goodness-of-fit can be improved by using the asymmetric case and proposes the use of the Anderson-Darling test. We utilize Chi-square, Anderson-Darling and Kolmogorov-Smirnov (K-S) goodness-of-fit tests for the stock market indices of ten emerging markets. 
We apply a Chi-square goodness-of-fit test by dividing the range of log-return values into subintervals. To make our analysis comparable, we follow the same class intervals considered in Madan and Seneta (1987), given by $\{-\infty,-1.0,-0.75,0.25,0$, $0.25,0.75,1.00, \infty\}$.

We denote the number of values falling into the $i$ th region as $N p_{i}$, where $N$ is the sample size and $p_{i}$ is the probability of a randomly drawn value to fall into the $i$ th region. Let $o_{i}$ denote the observed number of values in the $i$ th region, then we have the Chi-square test statistic defined over $k$ different regions as:

$$
\chi_{k-1-m}^{2}=\sum_{i=1}^{k} \frac{\left(o_{i}-N p_{i}\right)^{2}}{N p_{i}}
$$

where $m$ is the number of parameters of the model.

The Anderson-Darling (1952) goodness-of-fit test is a modification of the K-S test and attaches higher weights to the tails than the K-S test. The Anderson-Darling test statistic is calculated as:

$$
\begin{aligned}
& A^{2}=-N-S \text { where } \\
& S=\sum_{i=1}^{N} \frac{2 i-1}{N}\left[\ln F\left(X_{i}\right)+\ln \left(1-F\left(X_{N+1-i}\right)\right],\right.
\end{aligned}
$$

$X_{1}<X_{2}<\ldots .<X_{N}$ are the ordered log-returns, and $F(\cdot)$ is the cumulative distribution function and $N$ is the sample size. The test statistic, $A^{2}$, can be compared to the critical values of the normal distribution given in Stephens (1974). ${ }^{[2]}$

The Kolmogorov-Smirnov test statistic is given as:

$$
K S=\max _{1 \leq i \leq N}\left\{F\left(X_{i}\right)-\frac{i-1}{N}, \frac{i}{N}-F\left(X_{i}\right)\right\},
$$

where $F(\cdot)$ is the theoretical cumulative distribution function of the distribution being tested. Since we estimate the model parameters from the same initial dataset, the critical values of the K-S test cannot be used. However, the K-S test statistic can be used to quantify the fit of the VG model in comparison to the normal distribution.

Goodness-of-fit test statistics are presented in Table 5. The VG model fits the data well for most of emerging the markets with low Chi-square and Anderson-Darling test statistics, indicating that the distance between empirical and theoretical distributions are small. We observe that the Chi-square goodness-of-fit test rejects the VG model at the $99 \%$ confidence level only for Russia and Indonesia; whereas for Turkey, China, India, Brazil, Malaysia, and Thailand, we fail to reject the VG model at the $95 \%$ confidence level.

We also provide plots of the empirical distributions of log-returns with superimposed normal and VG probability density functions in Figure 1. The proximity of empirical and theoretical distributions verifies the goodness-of-fit of the VG model.

[2] The critical values of the Anderson-Darling test are not available for the VG model. 
Table 5

Chi-square and Anderson-Darling Goodness-of-fit Test Statistics for Daily Log-returns Critical values for Chi-square goodness-of-fit test for normal distribution are given as 12.59 and 16.81 for $95 \%$ and $99 \%$ confidence levels, respectively, whereas for the VG distribution the critical values are given as 9.49 and 13.28 for the same confidence levels. (*) indicates rejection at a $5 \%$ level and (**) indicates rejection at a $1 \%$ level.

\begin{tabular}{l|l|l|l|l|l|l}
\hline & Chi-Square & & Anderson-Darling & & Kolmogorov-Smirnov & \\
\hline & Normal & VG & Normal & VG & Normal & VG \\
\hline Turkey & $269.08^{* *}$ & 7.67 & 49.33 & 1.26 & 0.0738 & 0.0138 \\
\hline China & $289.91^{* *}$ & 6.32 & 39.68 & 0.40 & 0.0691 & 0.0103 \\
\hline India & $212.97^{* *}$ & 4.01 & $\infty$ & 0.60 & 0.0610 & 0.0100 \\
\hline Brazil & $145.54^{* *}$ & 7.67 & $\infty$ & 1.38 & 0.0585 & 0.0138 \\
\hline Russia & $446.73^{* *}$ & $16.36^{* *}$ & $\infty$ & 2.76 & 0.0973 & 0.0179 \\
\hline Indonesia & $357.97^{* *}$ & $18.91^{* *}$ & 58.54 & 1.88 & 0.0813 & 0.0178 \\
\hline Malaysia & $210.87^{* *}$ & 8.03 & $\infty$ & 5.82 & 0.0800 & 0.0124 \\
\hline Thailand & $264.24^{* *}$ & 8.04 & 41.74 & 0.90 & 0.0652 & 0.0125 \\
\hline $\begin{array}{l}\text { South } \\
\text { Africa }\end{array}$ & $144.77^{* *}$ & $11.70^{*}$ & 24.58 & 1.04 & 0.0492 & 0.0112 \\
\hline Mexico & $294.46^{* *}$ & $12.88^{*}$ & 44.27 & 0.97 & 0.0671 & 0.0135 \\
\hline
\end{tabular}

Figure 1

\section{Fitted Normal Distribution vs. the VG Distribution for Daily Log-returns} of Considered Emerging Stock Market Indices
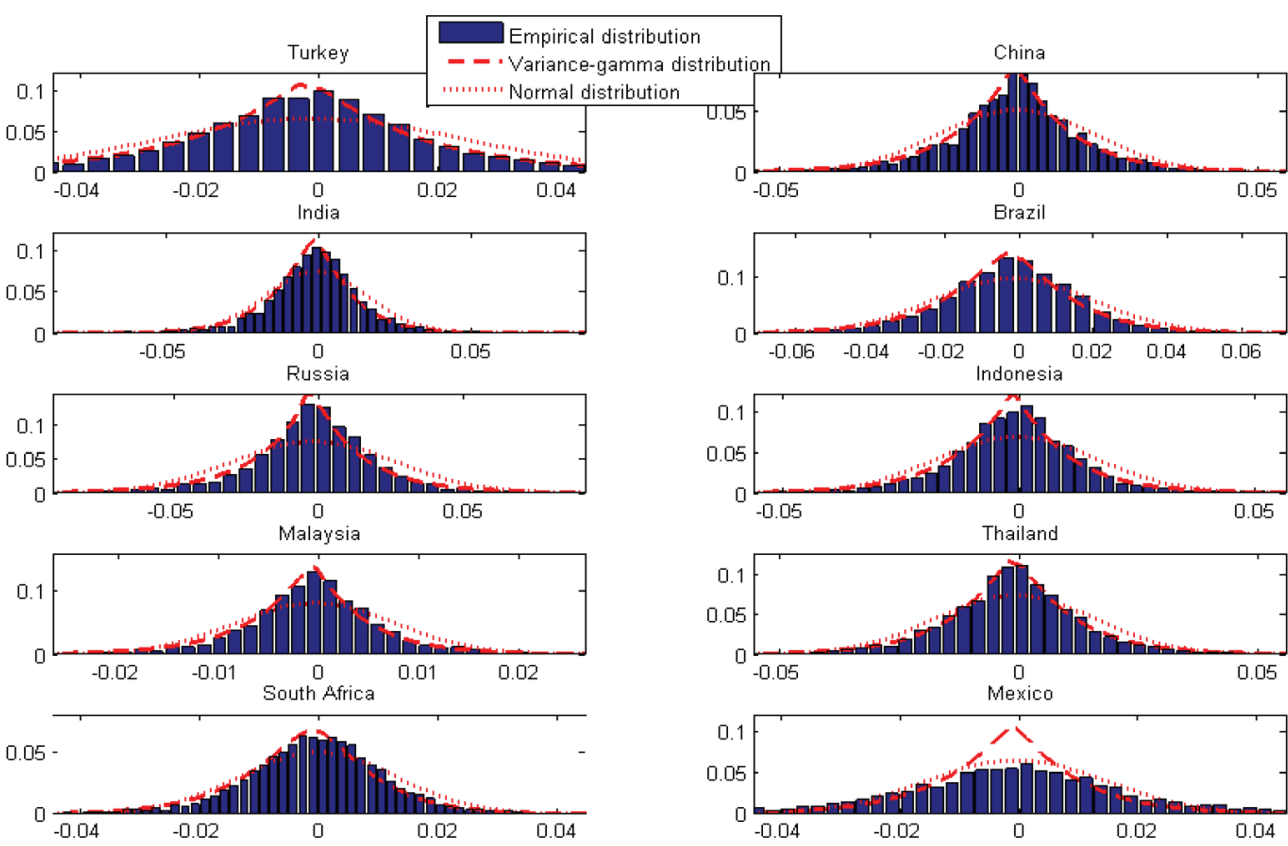


\section{Conclusion}

In this study, we evaluate the performance of the VG model for ten emerging stock market indices. Although the VG model is extensively used in practice, to the best of our knowledge this study is the first to question the validity of the distributional assumptions of the VG model for emerging markets.

We provide empirical evidence that the probability density function implied by the VG model provides a better fit than the normal distribution for emerging markets. Thus, for the purposes of financial derivative pricing in emerging markets, the VG model is superior to the Black-Scholes model in terms of its fit to the historical returns.

\section{References}

Anderson, T.W. and Darling, D.A. (1952). "Asymptotic Theory of Certain "Goodness of Fit" Criteria Based on Stochastic Processes," Annals of Mathematical Statistics, 23: 193-212.

Barndorff-Nielsen, O. (1997). "Normal Inverse Gaussian Distributions and Modeling of Stock Returns," Scandinavian Journal of Statistics, 24: 1-13.

-----, (1998). "Processes of Normal Inverse Gaussian Type. Finance and Stochastics," 2: 41-68.

Bekaert, G. and Harvey, C.R. (1995). “Time-Varying World Market Integration,” The Journal of Finance, 50(2): 403-444.

-----, (1997). "Emerging Equity Market Volatility," The Journal of Financial Economics, 43: 29-77.

Bekaert, G., Harvey, C.R., and Lundblad, C. (2009). "Liquidity and Expected Returns: Lessons from Emerging Markets," Review of Financial Studies, 20: 1783-1831.

Bibby, M. and Sorensen, M. (2003). "Hyperbolic Processes in Finance," in: S.T. Rachev (ed.), Handbook of Heavy Tailed Distributions in Finance. Amsterdam: Elsevier.

Carr P., Hogan A., and Stein, H. (2007). “Time for a Change: The Variance Gamma Model and Option Pricing," Working Paper.

Cont, R. (2001). "Empirical Properties of Asset Returns: Stylized Facts and Statistical Issues," Quantitative Finance, 1: 223-236.

Daal E.A. and Madan D.B. (2005). "An Empirical Examination of the Variance-Gamma Model for Foreign Currency Options," The Journal of Business, 78(6): 2121-2152.

Engle R.F. and Rangel J.G. (2008). "The Spline-GARCH Model for Low-Frequency Volatility and Its Global Macroeconomic Causes,” The Review of Financial Studies, 21(3): 1187-1222.

Finlay R. (2009). “The Variance Gamma (VG) Model with Long Range Dependence,” Unpublished Ph.D. Dissertation. University of Sydney, School of Mathematics and Statistics.

Fragiadakis, K., Karlis, D., and Meintanis, S.G. (2013). "Inference Procedures for the Variance Gamma Model and Applications," Journal of Statistical Computation and Simulation, 83(3): 555-567.

Gencay, R. and Selçuk, F. (2004). "Extreme Value Theory and Value-At-Risk: Relative Performance In Emerging Markets, ”International Journal of Forecasting, 20: 287-303.

Harvey C.R. (1995). "Predictable Risk and Returns in Emerging Markets," The Review of Financial Studies, 8(3): 773-816. 
Hitaj, A. and Mercuri, L. (2013). "Portfolio Allocation using Multivariate Variance Gamma Models," Financial Markets and Portfolio Management, 27(1): 65-99.

Hurst, S.R. and Platen, E. (1997). "The Marginal Distributions of Returns and Volatility," Lecture Notes-Monograph Series, 31: 301-314.

Li, X-M. and Rose, L.C. (2009). "The Tail Risk of Emerging Stock Markets," Emerging Markets Review, 10: 242-256.

Madan, D.B. and Seneta, E. (1987). "Chebyshev Polynomial Approximations and Characteristic Function Estimation," Journal of Royal Statistical Society B, 49: 163-169.

-----, (1990). “On Modelling and Pricing Weather Derivatives,” The Journal of Business, 63 (4): 511-524.

Madan, P., Carr, P., and Chang, E. (1998). “Variance Gamma Process and Option Pricing," European Finance Review, 2: 79-105.

Press, S.J. (1967). "A Compound Events Model for Security Prices," The Journal of Business, 40(3):317-335.

Rathgeber, A., Stadler, J., and Stockl, S. (2013). "Modeling Share Returns: an Empirical Study on the Variance Gamma Model," European Financial Management Association

Reading Meeting, (2013). Annual Meetings June 26-29, 2013.

Santis D. and Imrohoroğlu, S. (1997). "Stock Returns and Volatility in Emerging Financial Markets," Journal of International Money and Finance, 16(4): 561-579.

Seneta, E. (2004). "Fitting the Variance Gamma Model to Financial Data," Journal of Applied Probability, 4: 177-187.

------, 2009). "Variance Gamma Model,” Encyclopedia of Quantitative Finance.

Stephens, M.A. (1974). "EDF Statistics for Goodness of Fit and Some Comparisons," Journal of the American Statistical Association, 69: 730-737. 